\title{
Biosynthesis of zinc oxide nanoparticles using leaf extract of Calotropis gigantea: characterization and its evaluation on tree seedling growth in nursery stage
}

\author{
Sadhan Kumar Chaudhuri ${ }^{1} \cdot$ Lalit Malodia $^{1}$
}

Received: 6 February 2017/ Accepted: 18 August 2017/Published online: 8 September 2017

(c) The Author(s) 2017. This article is an open access publication

\begin{abstract}
Green synthesis of zinc oxide nanoparticles was carried out using Calotropis leaf extract with zinc acetate salt in the presence of $2 \mathrm{M} \mathrm{NaOH}$. The combination of $200 \mathrm{mM}$ zinc acetate salt and $15 \mathrm{ml}$ of leaf extract was ideal for the synthesis of less than $20 \mathrm{~nm}$ size of highly monodisperse crystalline nanoparticles. Synthesized nanoparticles were characterized through UV-Vis spectroscopy, dynamic light scattering (DLS), X-ray diffraction (XRD), Fourier transform infrared spectroscopy (FTIR), scanning electron microscopy (SEM), EDX (energy dispersive X-ray), and AFM (atomic force microscopy). Effects of biogenic zinc oxide $(\mathrm{ZnO})$ nanoparticles on growth and development of tree seedlings in nursery stage were studied in open-air trenches. The UV-Vis absorption maxima showed peak near $350 \mathrm{~nm}$, which is characteristic of $\mathrm{ZnO}$ nanoparticles. DLS data showed that single peak is at $11 \mathrm{~nm}(100 \%)$ and Polydispersity Index is 0.245 . XRD analysis showed that these are highly crystalline $\mathrm{ZnO}$ nanoparticles having an average size of $10 \mathrm{~nm}$. FTIR spectra were recorded to identify the biomolecules involved in the synthesis process, which showed absorption bands at 4307, 3390, 2825, 871, 439, and $420 \mathrm{~cm}^{-1}$. SEM images showed that the particles were spherical in nature. The presence of zinc and oxygen was confirmed by EDX and the atomic \% of zinc and oxygen were 33.31 and 68.69 , respectively. 2D and 3D images of $\mathrm{ZnO}$ nanoparticles were obtained by AFM studies, which indicated that
\end{abstract}

Sadhan Kumar Chaudhuri

skcdrdo@gmail.com

1 Visual Camouflage Group, Camouflage Division, Defence Laboratory Jodhpur, Defence Research and Development Organization, Ratanada Palace, Jodhpur, Rajasthan 342011, India these are monodisperse having size ranges between 1.5 and $8.5 \mathrm{~nm}$. Significant enhancement of growth was observed in Neem (Azadirachta indica), Karanj (Pongamia pinnata), and Milkwood-pine (Alstonia scholaris) seedlings in foliar spraying $\mathrm{ZnO}$ nanoparticles to nursery stage of tree seedlings. Out of the three treated saplings, Alstonia scholaris showed maximum height development.

Keywords Calotropis leaf $\cdot \mathrm{ZnO}$ nanoparticle $\cdot$ DLS · XRD · FTIR - SEM with EDS · AFM · Tree seedling growth

\section{Introduction}

In the recent years, the use of metal nanoparticles gained greater interest due to their diverse applications in the field of medicine, biology, physics, chemistry, and material sciences (Kumar et al. 2014). Nanotechnology can be defined as manipulation of matter through certain chemical and/or physical processes to create materials with specific properties which can be used in particular applications. Nanoparticles can be defined as particles that have at least one dimension less than $100 \mathrm{~nm}$ in size (Thakkar et al. 2014). Unlike bulk materials, they have unique optical, thermal, electrical, chemical, and physical properties. Hence, they find a variety of applications in the areas of medicine, chemistry, environment, energy, agriculture, information and communication, heavy industries, and consumer goods (Panigrahi et al. 2004). In recent years, nanotechnology has emerged as a state-of-theart and cutting-edge technology with multifarious applications in a wide array of fields. It is a very broad area comprising nanomaterials, nanotools, and nanodevices. Amongst nanomaterials, majority of the research has mainly focused on nanoparticles as they can be easily prepared and manipulated. 
Physical and chemical methods are conventionally used for the synthesis of nanoparticles; however, due to several limitations of these methods, such as use of toxic compounds, requirement of very high temperature and pressure, high expense, and time consumption, research focus has recently shifted towards the development of clean and eco-friendly synthesis protocols (Herlekar et al. 2014). It has been demonstrated that many biological systems including higher plants and algae, diatoms, bacteria, yeasts, fungi, and human cells can transform inorganic metal ions into metal nanoparticles via the reductive capacities of the proteins and metabolites present in these organisms. But synthesis of nanoparticles using microbes is difficult because it involves elaborate process of maintaining cell cultures, intracellular synthesis, and multiple purification steps. Hence, it is significant to note that the nanoparticle production using plant displays important advantages over other biological systems as plants are easily available and the procedure of biogenic synthesis is cost effective and less tedious as compared to biosynthesis using fungal source, which requires very long, tedious, and aseptic culture. The active biological compound present in plant parts like enzyme itself acts as a reducing and capping agent, thereby reducing the overall cost of synthesis process (Jain et al. 2009). In addition to enzymes, other biomolecules such as flavanoids, terpenoids, glycosides, alkaloids, inositols, resins, saponins, terpenes, volatile oil, tannins, steroids, and quinine also act as reducing and capping agents. In biogenic synthesis method, small nanoparticles can be produced during large-scale production (Kajbafna et al. 2009), and external experimental conditions like high energy and high pressure are not required causing significant energy saving (Kajbafna et al. 2012). Zinc oxide is an inorganic compound with the molecular formula $\mathrm{ZnO}$. It appears as white powder and is nearly insoluble in water. The powder $\mathrm{ZnO}$ is widely used as an additive in numerous materials and products including ceramics, glass, cement, rubber, paints, plastics, lubricants, adhesives, ointments, sealants, pigments, food, batteries, ferrites, and fire retardants. In the earth crust $\mathrm{ZnO}$ is present as zincite mineral but mostly $\mathrm{ZnO}$ used for commercial purposes is produced synthetically. Nowadays, the unique properties of nanomaterials have motivated the researchers to develop many simpler and inexpensive techniques to produce nanostructures of technologically important materials. Several metal oxide nanoparticles are produced with possible future applications. Among them, $\mathrm{ZnO}$ is considered to be one of the best exploited at nanodimensions. The wide band gap and large excitonic binding energy have made $\mathrm{ZnO}$ important both for scientific and industrial applications (Wang et al. 2004). $\mathrm{ZnO}$ nanoparticles have fascinated research interest and a lot of work has been done using various plant sources. Leaf extract of Calotropis gigantea using $\mathrm{ZnNO}_{3}$ salt produced nanoparticles of size $30-35 \mathrm{~nm}$ (Vidya et al. 2013). $\mathrm{ZnO}$ nanoparticle of size 100-200 nm were produced by zinc acetate salt with Acalypha indica leaf extract (Gnanasangeetha and Thambwani 2013). Parthenium hysterophorus leaf extract with $\mathrm{ZnNO}_{3}$ salt produced $\mathrm{ZnO}$ nanoparticles of 16-108 nm size (Sindhura et al. 2014). ZnO nanoparticles of size ranging from 30 to $35 \mathrm{~nm}$ were produced using Hibiscus rosasinensis with $\mathrm{ZnNO}_{3}$ salt (Devi and Gayathri 2014). Zinc acetate salt with leaf extract of Azadirachta indica produced $\mathrm{ZnO}$ nanoparticle of size $25 \mathrm{~nm}$ (Oudhia et al. 2015). Peel extract of Punica granatum with $\mathrm{ZnNO}_{3}$ salt produced $\mathrm{ZnO}$ nanoparticle (Mishra and Sharma 2015). Murraya koengii leaf extract with $\mathrm{ZnNO}_{3}$ salt produced $\mathrm{ZnO}$ nanoparticle of size $50 \mathrm{~nm}$ (Divyapriya et al. 2014). Leaf extract of Camellia sinensis with zinc acetate salt produced $\mathrm{ZnO}$ nanoparticle of size $16 \mathrm{~nm}$ (Senthilkumar and Sivakumar 2014). Extensive research is going on for commercializing $\mathrm{ZnO}$ nanoparticles throughout the world due to their unique properties. Olea europa leaf extract with $\mathrm{ZnSO}_{4}$ salt produced $\mathrm{ZnO}$ nanoparticles of $20 \mathrm{~nm}$ diameter (Awwad et al. 2014). $\mathrm{ZnO}$ nanoparticles of size less than $50 \mathrm{~nm}$ were synthesized using dried sap of roots and shoots of Astragalus gummifer (Darrudi et al. 2013). Biosynthesis of $\mathrm{ZnO}$ nanoparticle of size ranging from 50 to $200 \mathrm{~nm}$ was done using Citrus aurantifolia with zinc acetate salt (Samat and Nor 2013).

Nanofertilizer technology is very innovative but scantly reported literature is available in scientific journals. Substituting nanofertilizer for traditional methods of fertilizer application is a way to release nutrients into the plants in a gradually and controlled manner, thus preventing autrification and pollution of water resources (Naderi and Abedi 2012). There has been a wide use of chemical products such as fertilizers and minerals which are used to increase the yield of various products in the field at the same time. These chemicals result in various side effects in the plants and soil, and harm the environment in different ways. Nano-ZnO particle $(20 \mathrm{~nm})$, nano-FeO $(100 \mathrm{~nm})$, and nano- $\mathrm{CuO}(40 \mathrm{~nm})$ at ppm level showed increased shoot and root length in Mung seedling by foliar spray (Dhoke et al. 2013). Foliar spray method is more practical for an agronomic standpoint as plants can absorb essential elements through their leaves more efficiently compared to root feeding. Biologically synthesized $\mathrm{ZnO}$ nanoparticles are quickly transported through the plant and included in the metabolic processes. Mungbean seed germination in lowest concentration $(20 \mathrm{mg}$ ) of $\mathrm{ZnO}$ suspension solution showed good shoot and root growth results (Jayarambabu et al. 2014). Silver nanoparticles synthesized from banana (Musa balbisiana), neem (Azadirachta indica), and black tulsi (Ocimum tenuiflorum) showed significant increase in the root and shoot length of germinated seedlings of Mung bean (Vigna radiata) and Chickpea (Cicer arietinum) (Banerjee et al. 2014). Nanofertilizer technology is very innovative as some reports and patents strongly suggest 
that there is a vast scope of formulation of nano-fertilizers. Central Arid Zone Research Institute, Jodhpur, developed the infrastructure and standardized biosynthesis methods for synthesis and characterization of large number of nanonutrients and their effective use in crop improvement. Significant increase in yield was observed in Pearl Millet (Pennisetum americanum) due to foliar application of zinc oxide nanoparticles as fertilizer (Tarafdar et al. 2014). Currently, research is underway to develop nanocomposite to supply all the essential nutrients in suitable proportion through smart delivery system. Preliminary results suggest that balanced fertilization may be achieved through nanotechnology (Tarafdar et al. 2012). Nanofertilizer nutrients can be encapsulated by nanomaterial cooled with a thin protective film or delivered as emulsions or nanoparticles. Nanomaterials could even be used to control the release of the fertilizer such that the nutrients are only taken up by the plants and not lost to unintended targets like soil, water, or microbes. Recent reports indicated that biosynthesized silver nanoparticles using seed exudates of Spinosa arvensis showed antifungal (Neofusicoccum parvum) activities (Khatami et al. 2015) and may be responsible for increased seed germination.

The plant Calotropis gigantean belonging to the family Asclepiadaceae, also called as Akra, Shwet akra, and Madara, is distributed throughout India, especially in dry vast land. The different parts of the plant are used in Indian traditional medicine for the treatment of painful muscular spasm, dysentery, fever, rheumatism, asthma, and as an expectorant and purgative. Bioactive compounds such as 15 $\beta$-hydroxycardenolides $(1,2)$ and a $16 \alpha$-hydroxycalactinic acid methyl ester (3) along with eleven known compounds including $16 \alpha-$ hydroxycalotropagenin, coroglaucigenin, 16 $\alpha$-hydroxycalotropin, calactinic acid, calotoxin, desglucouzarin, 12 $\beta$ hydroxycoroglaucigenin, frugoside, calotropagenin, dienoic acid, and mevalonolactone are found in the leaves of this plant (Singh et al. 2011). Calotropis yields a durable fiber that is useful for ropes, carpets, fishing nets, and sewing thread. Floss, obtained from seeds, is used for stuffing purposes. Extracts of different plant parts such as root, stem, and leaf affect germination and seedling vigor of many agricultural crops. It is also used as green manure and improves soil nutrients and improves moisture binding capacity of soil. The plant is tolerant of dry and salty conditions and can easily be established in over-cultivated areas to help improve the soil conditions and reinvigorate the land (Seeka and Sutthivaiyakit 2010). Moreover, this plant is widely distributed predominantly in Thar Desert area of Rajasthan. Hence, such medicinal and commercial uses of Calotropis plants have increased our interest and lead us to work on this plant species. Biosynthesis of nanoparticles is an exciting recent addition to the large repertoire of nanoparticle synthesis methods and now nanoparticles have entered a commercial exploration period.
Gold, silver, copper, and zinc have been used mostly for the synthesis of stable dispersions of nanoparticles, which are useful in areas such as photolysis, diodes, piezoelectric devices, fluorescent tubes, laser, sensor, photography, biological labeling, photonics, and surface-enhanced Raman scattering detection. Till date, use of $\mathrm{ZnO}$ nanoparticles is mainly restricted in agriculture applications for enhanced productivity in crop plants. But there is not a single report showing the use of $\mathrm{ZnO}$ nanoparticles in nursery stage for enhanced growth and development of tree seedlings. Defence Laboratory Jodhpur is working on arboriculture camouflage for military applications in the desert area of Rajasthan. In the desert area of Rajasthan, the growth of trees is very slow due to adverse climatic conditions (high temperature up to $50{ }^{\circ} \mathrm{C}$, low humidity, less rainfall, and saline soil). To get enhanced growth and development, large canopy in short-time foliar spraying of $\mathrm{ZnO}$ nanoparticles may be desirous to overcome the climatic problems and enhanced growth and development of seedlings at nursery stage.

In this paper, we reported the biosynthesis of stable colloidal zinc oxide nanoparticles using leaf extract of $C$. gigantea. This plant is an important medicinal plant and predominantly distributed in Thar Desert area of Rajasthan. Details of biosynthesis, characterization, and its effects on enhanced growth and development of tree seedling in nursery stage are described.

\section{Materials and methods}

\section{Reagents}

Zinc acetate dihydrate (Lot \# MKBQ7110v) was obtained from Sigma-Aldrich and $\mathrm{NaOH}$ from E-Merck, India.

\section{Collection of plant material}

Fresh leaves of $C$. gigantea were collected from Defence Laboratory, Jodhpur campus $\left(26.2717^{\circ} \mathrm{N}, 73.0378^{\circ} \mathrm{E}\right)$. Collected leaves were thoroughly washed under tap water and then were washed with Milli-Q water and chopped with knife. The leaves were kept in oven for drying at $60{ }^{\circ} \mathrm{C}$ for 3 days, and dried leaves were powdered using home mixer blender and stored in an air-tight container at room temperature till further use.

\section{Preparation of leaf extract}

Glass goods and plastic wares were thoroughly cleaned in chromic acid and washed repeatedly in tap water followed by final wash in Milli-Q water before drying in hot air oven. Glass goods, plastic wares, and Milli-Q water 
required for biosynthesis and characterization of nanoparticles were autoclaved before use. $5 \mathrm{~g}$ of dried leaf powder was transferred to a $250-\mathrm{ml}$ beaker containing $100 \mathrm{ml}$ Milli-Q water and heated for $15 \mathrm{~min}$ at $60{ }^{\circ} \mathrm{C}$. The solution was kept for cooling at room temperature and then filtered using Whatman filter paper no. 1 . The filtrate was collected in amber bottle and was stored at $4{ }^{\circ} \mathrm{C}$ for further experiment.

\section{Biosynthesis of ZnO NPs}

$15 \mathrm{ml}$ of leaf extract of Calotropis was added to $2.195 \mathrm{~g}$ of zinc acetate dihydrate dissolved in $35 \mathrm{ml}$ of distilled water (overall concentration $200 \mathrm{mM}$ solution). The reaction mixture was kept on magnetic stirrer for $6 \mathrm{~h}$. After $6 \mathrm{~h}$, $2 \mathrm{M} \mathrm{NaOH}$ ( $4 \mathrm{~g}$ of $\mathrm{NaOH}$ pellet in $50 \mathrm{ml}$ of Milli-Q water) was added to the solution and it was placed in incubator at $60{ }^{\circ} \mathrm{C}$ with magnetic stirring for overnight. White mixture was centrifuged at $14,000 \mathrm{rpm}$ for $15 \mathrm{~min}$. Precipitate was subjected to washing with alcohol and distilled water three times each. Precipitate was dried in an incubator at $40-50{ }^{\circ} \mathrm{C}$ and fine powder was prepared with the help of ceramic pestle and mortar. Fine powder was used for characterization with AFM, SEM, FTIR, XRD, EDS, UVVis, and DLS.

\section{Characterization of biosynthesized ZnO NPs}

pH analysis

Zinc acetate aqueous solution (200 mM) showed $\mathrm{pH} 6.58$. $\mathrm{pH}$ of aqueous Calotropis leaf extract was 6.23. The changed $\mathrm{pH}$ of reaction mixtures was recorded using digital $\mathrm{pH}$ meter (Eutech Cyberscan pH 300) during the synthesis of zinc oxide nanoparticles.

\section{$U V-V i s$ spectroscopy}

The reduction of zinc ion was monitored by measuring optical density through UV-Vis spectroscopy of the reaction medium after diluting small aliquots of reaction mixture ten times diluted with Milli-Q water and transferred to cuvette, and analysis was done using UV-Vis spectrophotometer (Ocean Optics, USA).

Dynamic light scattering (DLS) analysis and zeta potential measurement

Particle size distribution and average size of zinc oxide nanoparticles were obtained through particle size analyzer. Liquid sample before centrifugation was diluted ten times using Milli-Q water and transferred to cuvette, and analysis was done using DLS (Malvern Zetasizer, Nano Z500 UK). The sample holder temperature was maintained at $25^{\circ} \mathrm{C}$. The measurements depend on the size of the particle core, surface structure, particle concentration, and the type of the ion in the mixture. The zeta potential of the synthesized nanoparticles was determined in water as dispersant.

\section{$X$-ray diffraction}

The formation and quality of compounds were investigated by X-ray diffraction technique. For this purpose, synthesized zinc oxide NPs were centrifuged $\left(1400 \mathrm{rpm} ; 8{ }^{\circ} \mathrm{C}\right)$ for $15 \mathrm{~min}$, pellet was washed three times with ethanol and finally with sterile Milli-Q water for three cycles. The purified $\mathrm{ZnO} N \mathrm{NP}$ precipitate was dried in oven at $60{ }^{\circ} \mathrm{C}$ and powdered with ceramic mortar-pestle. Powdered sample was analyzed using X-ray diffractometer (X'Pert PROPAN Analytical, Europe). The scanning was done in the region of $2 \theta$ from $20^{\circ}$ to $80^{\circ}$.

\section{FTIR analysis}

FTIR was used to identify the possible functional groups involved in the reduction of zinc ion and capping of reduced zinc oxide nanoparticles. FTIR spectrum was recorded using Shimadzu, Japan, infrared (IR) doublebeam spectrophotometer. FTIR analysis of dried $\mathrm{ZnO}$ nanoparticles (NPs) was carried out through potassium bromide $(\mathrm{KBr})$ pellet method in 1:30 ratios (NPs: $\mathrm{KBr})$ and spectrum was recorded in transmittance mode at a resolution of $4 \mathrm{~cm}^{-1}$. The peaks (stretching) obtained were plotted as transmittance in $Y$-axis and wave number $\left(\mathrm{cm}^{-1}\right)$ in $X$-axis. The spectrum was recorded in the wave number range $500-4500 \mathrm{~cm}^{-1}$ and analyzed subtracting the spectrum of pure $\mathrm{KBr}$.

\section{SEM analysis}

Scanning electron microscopy (SEM) analysis was carried out using Carl Zeiss Japan, model machine. Thin film of nanoparticle powder sample was prepared on carboncoated tape by adhering small amount of dried fine powder of sample on the grid, excess sample was removed with the help of blotting paper. The film on the SEM grid was allowed to dry by putting it under a mercury lamp for $5 \mathrm{~min}$. The SEM analysis was used to determine the surface structure of biogenically synthesized ZnO NPs.

\section{Energy-dispersive X-ray spectroscopy}

Sample used for SEM was used as it is and the same instrument was used. EDX analysis was carried out to 
determine the chemical purity, elemental composition, and stoichiometry of the synthesized zinc oxide nanoparticles.

\section{Atomic force microscopy}

Freshly cleaved mica sheet was adhered on substrate using double-sided tape. Diluted sample prepared using ultrasonicator was placed upon the substrate using drop technique with autoclaved microtip. This sample was placed and dried in incubator at $37{ }^{\circ} \mathrm{C}$ for $1 \mathrm{~h}$. Analysis was done using Z-03 scanner in AFM (NT-MDT Solver Pro, Russia).

\section{Evaluation of ZnO NP effects on tree seedling growth}

One-year-old saplings developed in Defence Laboratory, Jodhpur, nursery were used for the treatment of zinc oxide ( $\mathrm{ZnO})$ nanoparticles (NPs). Six trenches were prepared in a specific distance within the iron net house in open air. Hundred saplings of each species (Neem-Azadirachta indica, Milkwood-pine-Alstonia scholaris, and Tilpapra/ Karanj-Pongamia pinnata) were placed in control and treated sets (fifty saplings in each trench). Initial heights were recorded with measuring scale. Spraying of biogenic $\mathrm{ZnO} \mathrm{NPs}$ at $30 \mathrm{mg}$ per liter synthesized from Calotropis leaf extract was carried out through aerosol foliar spraying. The optimal concentration $(30 \mathrm{mg} / \mathrm{l})$ for seedling treatment was determined in tree seed germination studies (data not included here) before the nanoparticle foliar spray treatment. Watering of the trenches was carried out in specific interval in a general practice (twice a week) of nursery development. After 3 months of treatment, the height of each sapling was measured and spraying of $\mathrm{ZnO}$ NPs at $30 \mathrm{mg}$ per liter was done once again and after 6 months the final height of each sapling was recorded for statistical data analysis.

\section{Statistical data analysis}

Analytical determination was carried out from the average mean data of 50 plants in a set (control and treated). All experimental data were expressed as mean \pm standard error.

\section{Results and discussion}

\section{Color change}

Reduction of zinc is confirmed by color change of the reaction mixture from pale yellow to white (Fig. 1; Table 1).

\section{Variation in pH during biosynthesis of ZnO NPs}

$U V-v i s$ spectroscopy

Optical properties of $\mathrm{ZnO}$ nanoparticles were characterized using UV-Vis spectrophotometer. The UV-Vis absorption curve of $\mathrm{ZnO}$ nanoparticles is shown in Fig. 2. Zinc oxide formation was confirmed as the absorption peak (lambda $\max$ ) was found near $350 \mathrm{~nm}$. This result correlates with the already reported results, in which absorption peak was found at $360 \mathrm{~nm}$ (Jayarambabu et al. 2014) (Table 2).

\section{Dynamic light scattering analysis}

The size of synthesized zinc oxide nanoparticles when analyzed by DLS shows the mean size of synthesized $\mathrm{ZnO}$ nanoparticles as $11 \mathrm{~nm}(100 \%)$ in a single peak (Fig. 3) and Polydispersity Index (PDI) is 0.245.

\section{Zeta potential}

Figure 4 shows the measured zeta potential value of biosynthesized zinc oxide nanoparticles in the colloidal solution. The nanoparticles possess a negative zeta potential value of $-20.7 \mathrm{mV}$, which indicated that even after the storage of 3 months at room temperature these are highly stable due to electrostatic repulsive force. The high negative value confirms the repulsion among the particles and the negative indicates that nanoparticles are stable. Measurement of zeta potential depends on the movement of nanoparticles under influence of an applied electric field. This movement depends upon surface charge and the local environment of the particle.

\section{$X$-ray diffraction}

The dried powdered sample was used to perform XRD for confirming the size of $\mathrm{ZnO}$ nanoparticles. The graph (Fig. 5) showed main peaks corresponding to $2 \theta$ values of $32.25^{\circ}, 34.88^{\circ}, 36.70^{\circ}, 47.97^{\circ}, 56.99^{\circ}, 63.23^{\circ}, 66.79^{\circ}$, $68.33^{\circ}, 69.43^{\circ}$, and $77.39^{\circ}$. This result is almost similar to already reported results in $O$. europa leaf extracts in which $2 \theta$ values were obtained at $31.84^{\circ}, 34.50^{\circ}, 36.32^{\circ}, 47.59^{\circ}$, $56.63^{\circ}, 66.89^{\circ}, 67.98^{\circ}, 69.09^{\circ}$, and $76.98^{\circ}$ (Awwad et al. 2014). The size of nanoparticles was in the range of 8-12 $\mathrm{nm}$ and the average size of nanoparticles determined by XRD was $10 \mathrm{~nm}$ (using Debye-Scherrer equation).

\section{FTIR analysis}

To determine the functional groups responsible for the synthesis of $\mathrm{ZnO}$ NPs in $C$. gigantea leaf extract, FTIR analysis was performed. The FTIR spectrum of $C$. gigantea 

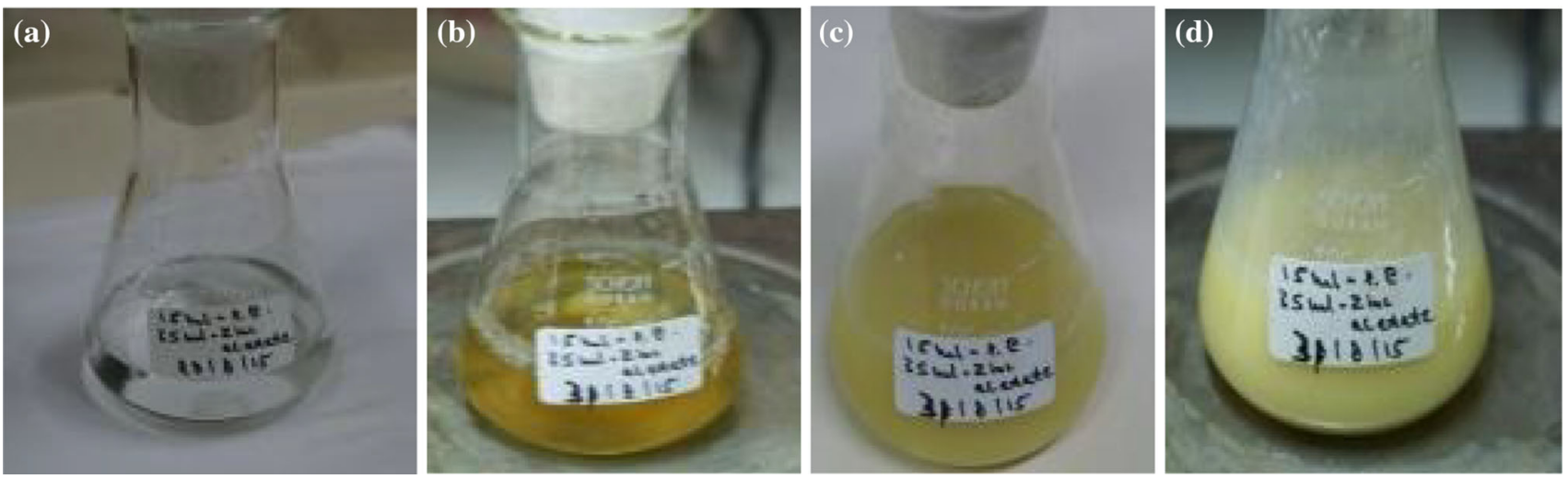

Fig. 1 a $200 \mathrm{mM}$ zinc acetate solution (transparent), b $35 \mathrm{ml}$ of zinc acetate solution $+15 \mathrm{ml}$ of leaf extract (yellowish white), c after $6 \mathrm{~h}$ (pale yellow color), $\mathbf{d}$ after $24 \mathrm{~h}$ (white color intensity increased)

Table 1 Change in color of solution during formation of zinc oxide nanoparticles using Calotropis leaf extract

\begin{tabular}{lllll}
\hline Solution & Before reduction & After reduction & Color intensity & \\
\hline Calotropis leaf extract & Light brown & & & Time \\
$200 \mathrm{mM}$ zinc acetate & Transparent & Pale yellow & + & $++\quad$ Immediate \\
& & Yellowish white & +++ & After $6 \mathrm{~h}$ \\
& & White & & After $24 \mathrm{~h}$ \\
\hline
\end{tabular}

Fig. 2 UV-vis absorption spectra of zinc acetate solution, plant extracts and synthesized $\mathrm{ZnO}$ nanoparticles after $24 \mathrm{~h}$

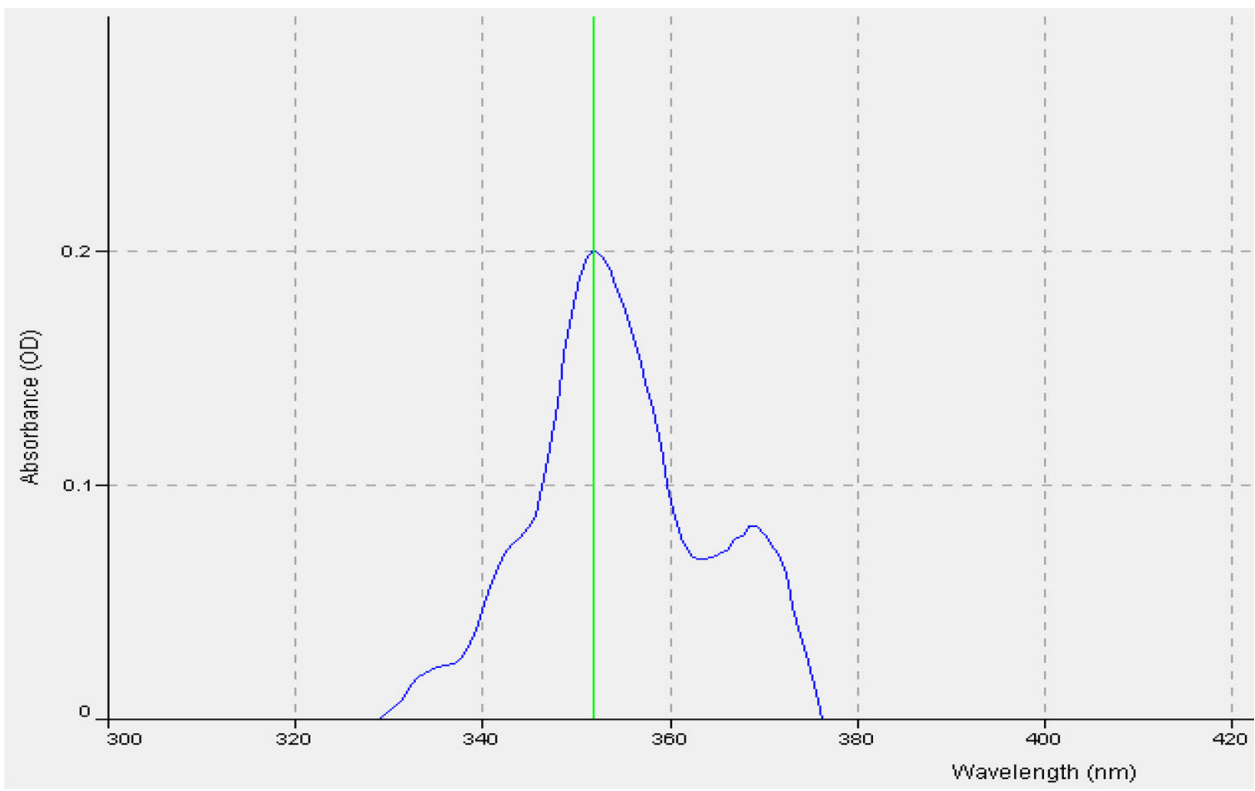

leaf extract is shown in Fig. 6, which shows absorption bands at 4307, 3390, 2825, 871, 439, and $420 \mathrm{~cm}^{-1}$ which are characteristic of $-\mathrm{OH}$ stretching vibration and $-\mathrm{CH}$ stretching vibration. The band at $871 \mathrm{~cm}^{-1}$ is due to asymmetrical and symmetrical stretching of zinc carboxylates resulting in the involvement of carboxylic groups in protein of Calotropis leaf extract. This result coincides with the already reported result of biosynthesis of $\mathrm{ZnO}$ nanoparticles using $O$. europa leaf extract (Awwad et al. 2014). Studies confirmed the presence of phytochemicals (eicosatrienoic acid methyl ester, hexatriacontaine, trimethyl undecatriene, and trifluoroacetic acid), volatile essential oil (phytol), and flavanoids (varinging, quercitrin, hesperitin, and kaempferol). It also contains acalyphamide, 2-methylanthraquinone, tri-o-methyl ellagic acid, sitosterol, glucoside, stigmasterol, quinine, tannins, resins, and 
Table 2 Change in $\mathrm{pH}$ of solution during formation of zinc oxide nanoparticles using Calotropis leaf extract

\begin{tabular}{lll}
\hline Solution & Before reduction $(\mathrm{pH})$ & After reduction $(\mathrm{pH})$ \\
\hline Calotropis leaf extract & 6.23 & - \\
$200 \mathrm{mM}$ zinc acetate & 6.58 & - \\
$15 \mathrm{ml}$ of leaf extract $+35 \mathrm{ml}$ of $200 \mathrm{mM}$ zinc acetate & 6.14 & $11.40($ after $6 \mathrm{~h})$ \\
& 11.12 (immediately after adding $\mathrm{NaOH})$ & $12.50(\mathrm{after} 24 \mathrm{~h})$ \\
\hline
\end{tabular}

Fig. 3 Size distribution and mean particle size of synthesized zinc oxide nanoparticles

Fig. 4 Zeta potential measurement

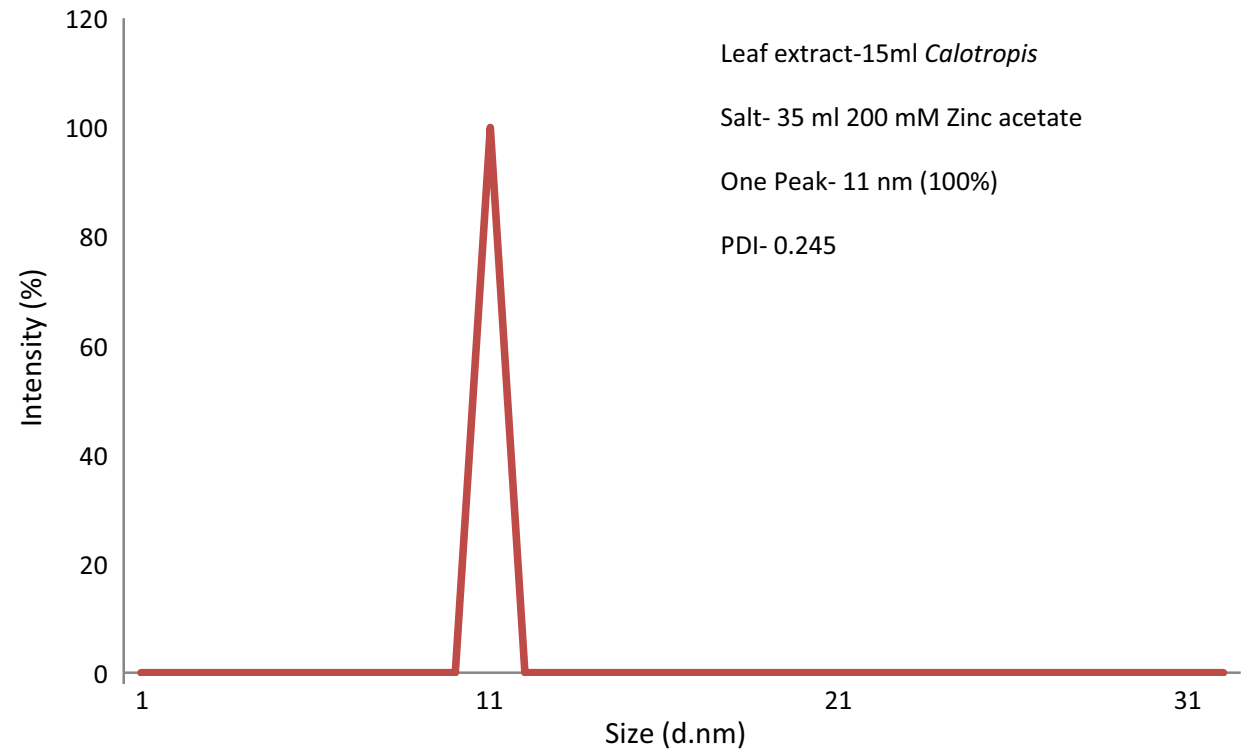

\begin{tabular}{|c|c|c|}
\hline & Mean (mV) & Area $\left(y_{0}\right)$ \\
\hline Zeta Potential (mV): -20.7 & Peak 1: - 20.7 & 100.0 \\
\hline Zeta Deviation (mV): 6.62 & Peak 2: 0.00 & 0.0 \\
\hline Conductivity (mS/cm): 0.101 & Peak 3: 0.00 & 0.0 \\
\hline
\end{tabular}

Result quality: Good

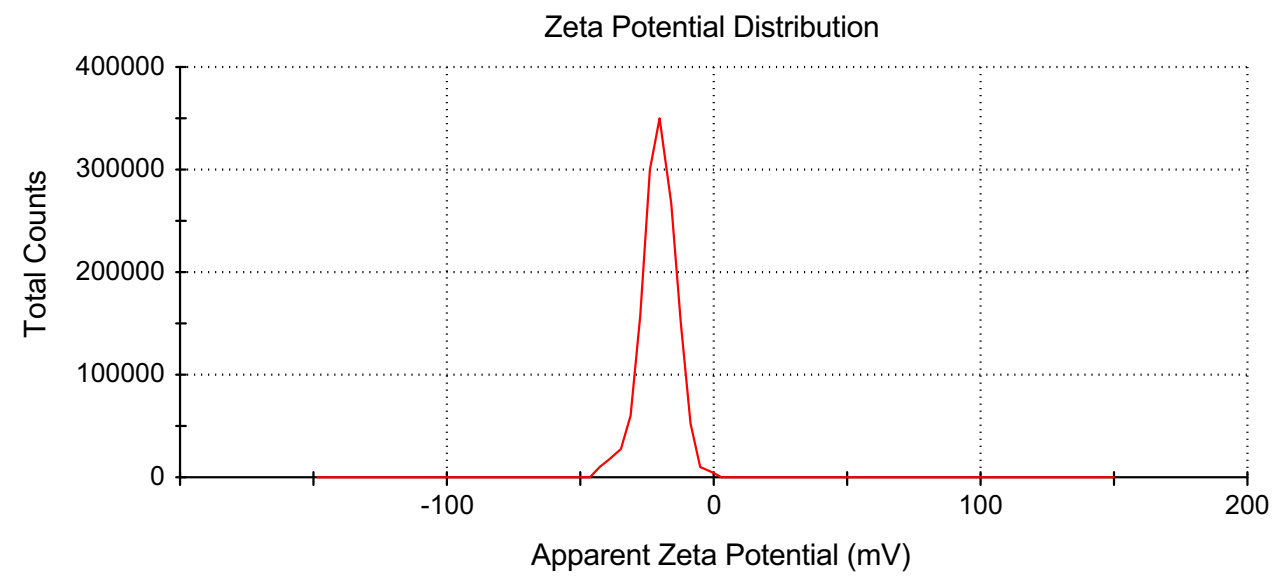




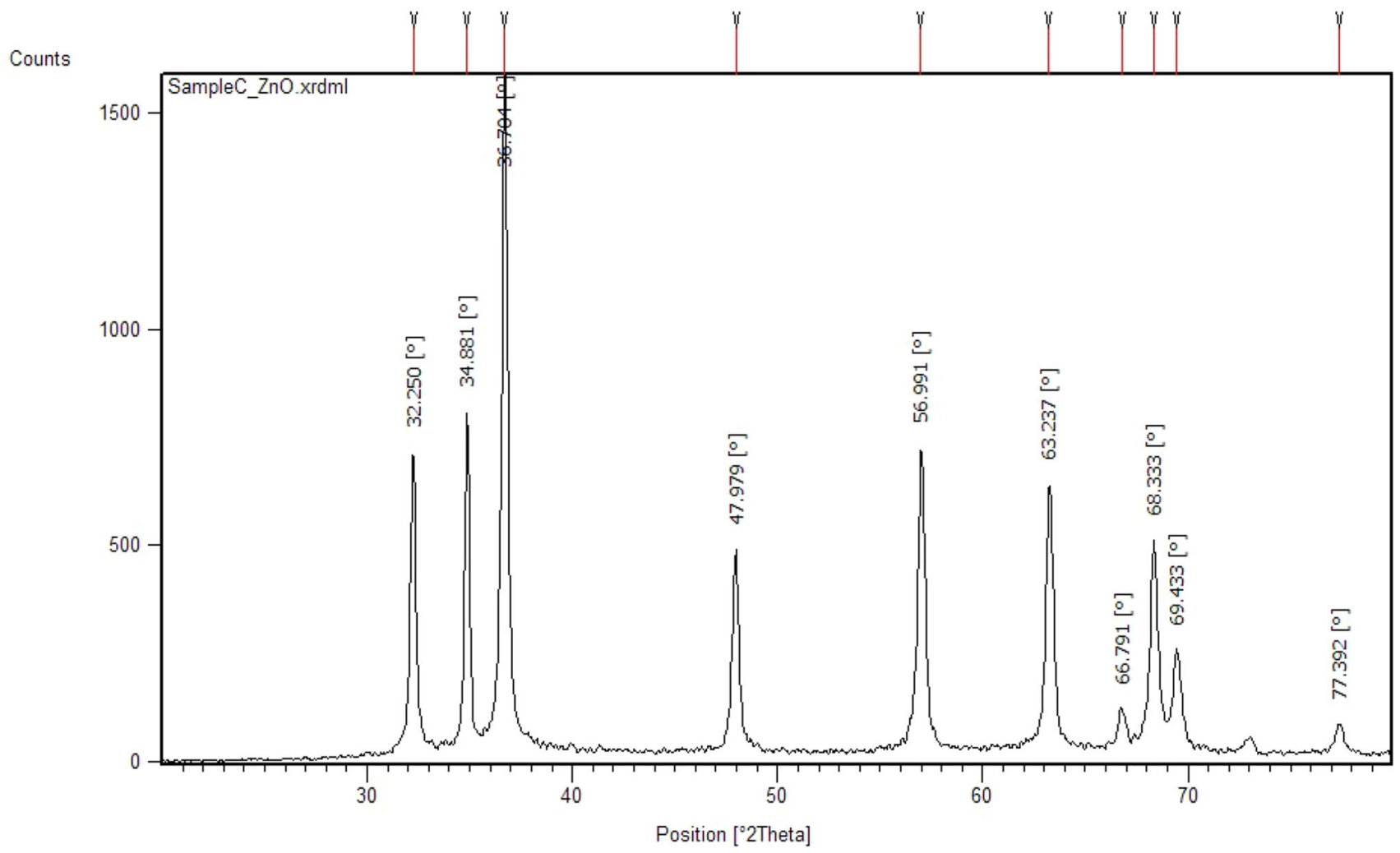

Fig. 5 XRD graph of biosynthesized zinc oxide nanoparticles

essential oils. Results inveterate that $-\mathrm{OH}$ stretching around $3390 \mathrm{~cm}^{-1}$ and $-\mathrm{CH}$ stretching around $2825 \mathrm{~cm}^{-1}$ are responsible for strong capping on the $\mathrm{ZnO}$ nanoparticles. This result matches with the already reported result of biosynthesis of $\mathrm{ZnO}$ nanoparticles using Acalypha indica leaf extract (Gnanasangeetha and Thambwani 2013).

\section{SEM analysis}

SEM was employed to analyze the structure of nanoparticles that were formed. SEM image has shown individual $\mathrm{ZnO}$ nanoparticles as well as a number of aggregates. SEM image in Fig. 7 shows that these are spherical-shaped nanoparticles. This SEM result coincides with results already reported, which shows formation of sphericalshaped nanoparticles and aggregated molecules in Calotropis leaf extract (Vidya et al. 2013).

\section{Energy-dispersive $X$-ray spectroscopy}

EDX analysis was carried out to determine the elemental composition and stereochemistry of the synthesized zinc oxide nanoparticles. In Fig. 8, zinc and oxygen signals detected that the synthesized nanoparticles are in pure state of chemical nature. The single peak of $\mathrm{Zn}$ and $\mathrm{O}$ is found between 0 and 2, and two peaks of $\mathrm{Zn}$ were found in between 8 and 10. These results correlate with the already reported results in which similar peaks have been observed in $\mathrm{ZnO} \mathrm{NP}$ synthesis using Acalypha indica leaf extract (Gnanasangeetha and Thambwani 2013).

Further analysis was done to find weight $\%$ and atomic $\%$ of zinc and oxygen elements present in the biogenically synthesized sample using Calotropis leaf extract (Table 3).

\section{Atomic force microscopy}

To validate the surface morphology of biogenic ZnO NPs, drop-coated two- and three-dimensional AFM images were taken in noncontact mode. Result showed variability in morphological features of biosynthesized zinc oxide nanoparticles (Fig. 9a, b). The sizes range from 1.5 to $8.5 \mathrm{~nm}$ and the particles are more or less homogeneous in size range and monodisperse nature.

\section{Evaluation of ZnO NP effects on tree seedling growth}

For studying the effects of ZnO NPs on growth and development of three important tree seedlings (Azadirachta indica, Alstonia scholaris, and $P$. pinnata) in nursery stage, they were treated with $\mathrm{ZnO}$ NPs at a final concentration of 
ФSHIMADZU

\section{CAZRI - JODHPUR}

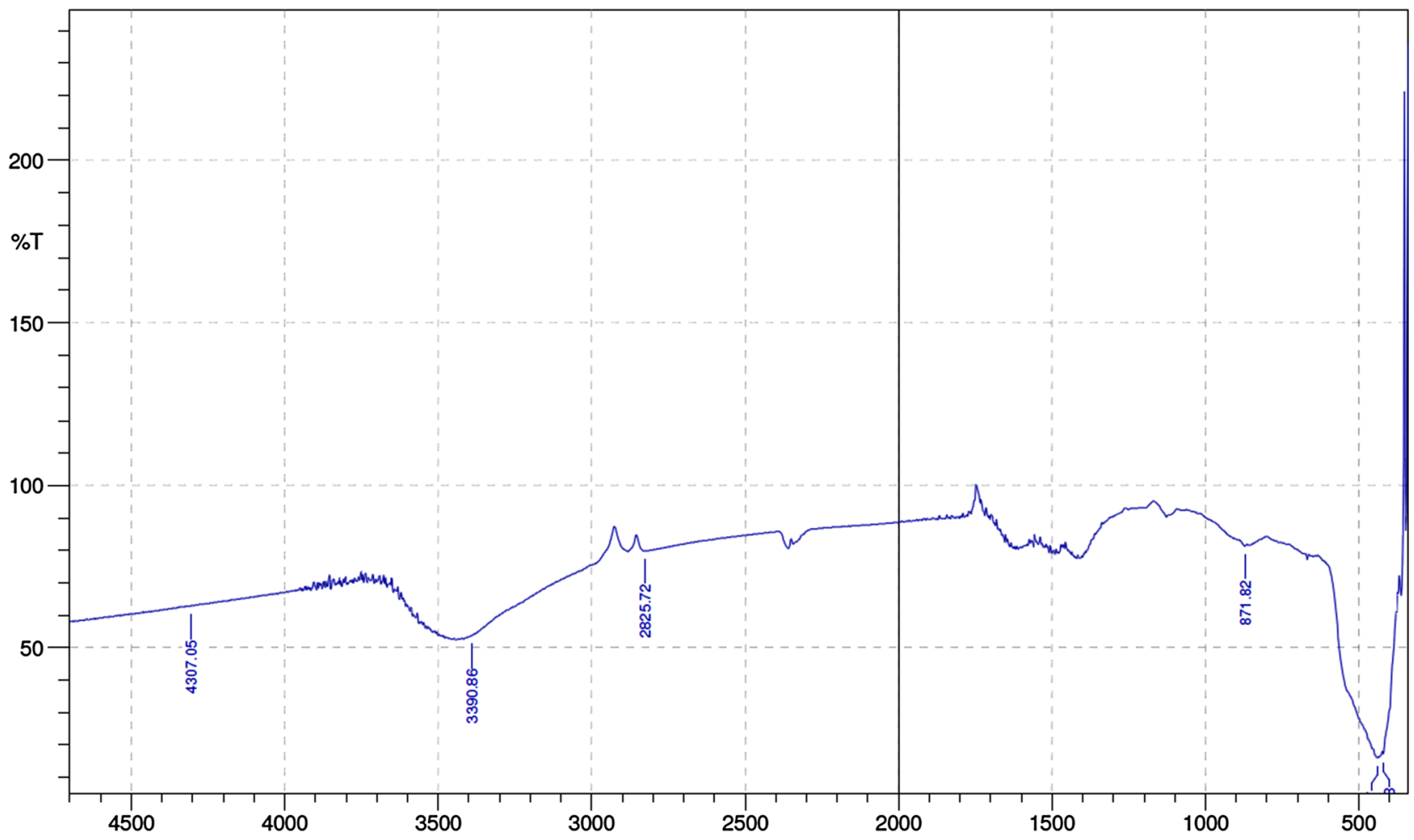

Fig. 6 FT-IR spectrum of the biosynthesized $\mathrm{ZnO}$ nanoparticles

Fig. 7 SEM image of zinc oxide nanoparticles

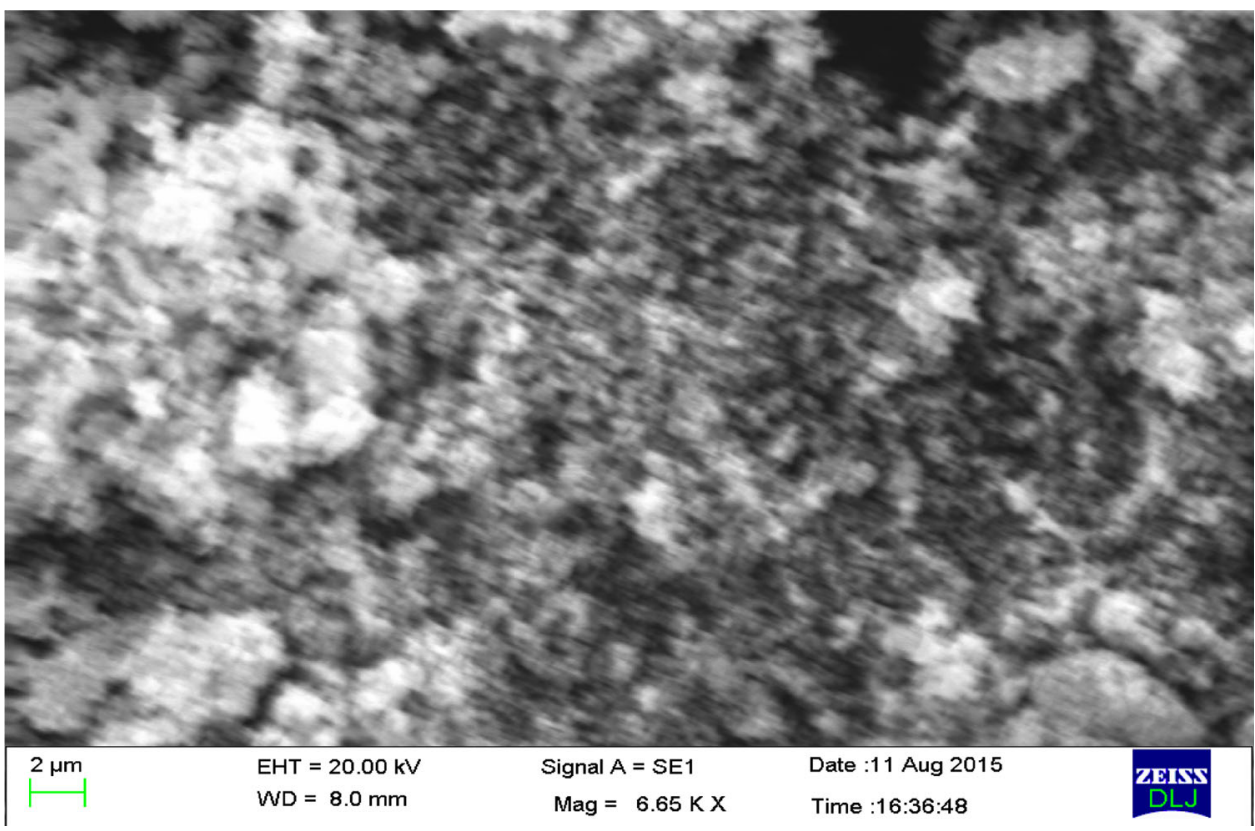

compared to control sets (Fig. 10). Significantly enhanced growth and development was evident in Alstonia scholaris compared to other two species (Fig. 11).
$30 \mathrm{mg} / \mathrm{l}$ for each treatment. After treatment, seedling growth in terms of plant height was measured. Increased height in all three plant species could be observed 
Fig. 8 EDS spectrum of synthesized zinc oxide nanoparticles

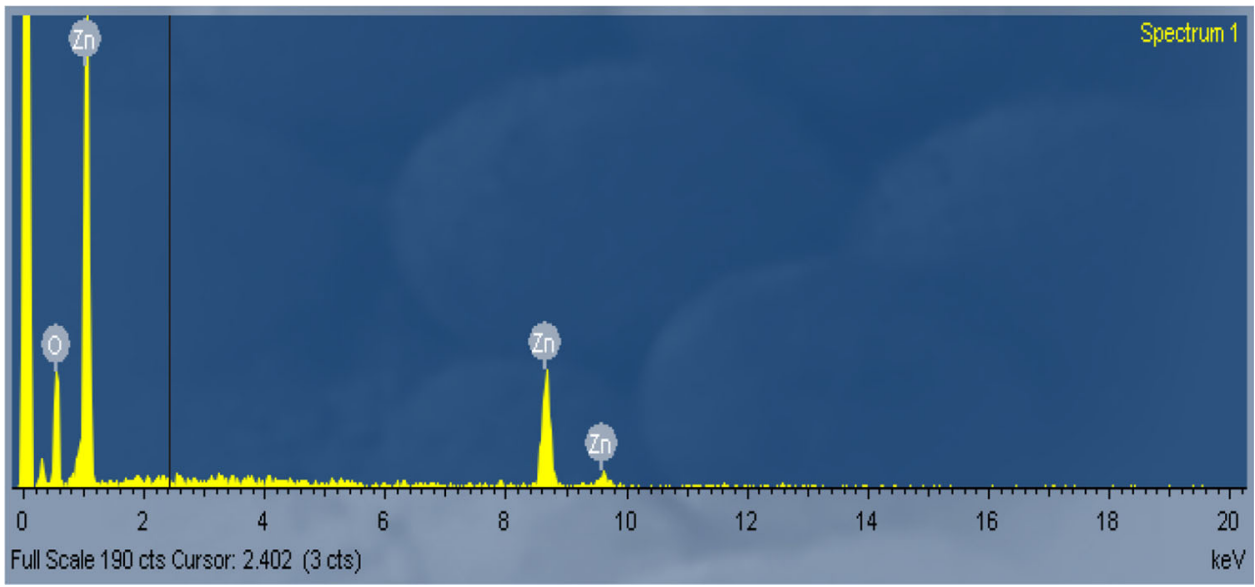

Table 3 EDX analysis showing weight $\%$ and atomic $\%$ of zinc and oxygen elements present in the sample

\begin{tabular}{lll}
\hline Element & Weight $\%$ & Atomic $\%$ \\
\hline Zinc & 59.85 & 31.31 \\
Oxygen & 40.15 & 68.69 \\
\hline
\end{tabular}

\section{Conclusions}

Green-synthesized nanoparticles have a potential role in the form of nanofertilizers in the current scenario, this work may help in future development of nanonutrients for plant growth and development. Recently, we have reported the potential use of endemic hot desert plant Rohida's leaf and flower (Tecomella undulata) extract for the synthesis of silver nanoparticles (Chaudhuri et al. 2016; Chaudhuri and Malodia 2017). In Thar Desert area of Rajasthan Calotropis plants are available throughout the year and they can easily survive in high temperature without any irrigation. So, Thar Desert bioresources can effectively be used for the biosynthesis of nanoparticles and their use as nanonutrients. The colloidal solution of zinc oxide nanoparticles is used as fertilizer for fast growth and development in tree seedlings. This type of nanofertilizer is a plant nutrient which is more than a conventionally used fertilizer because it not only supplies nutrients for the plant but also revives the soil to stay in organic state without any harmful factors of chemical fertilizers. One of the advantages of nanofertilizers is that they can be in very small amounts compared to chemical fertilizers. Nanopowders can be successfully used as fertilizers and pesticides as well for increased agricultural crop productivity. In the field of crop plant growth and yield, the role of various types of nanomaterials gradually increased. Nanoparticles are found to be effective in seed germination in lettuce and cucumber (Shah and Belozerova 2009; Barrena et al. 2009), and enhanced growth and yield in wheat (Razzaq et al. 2016). Enhanced seedling growth and diosgenin content (Jasim (a)

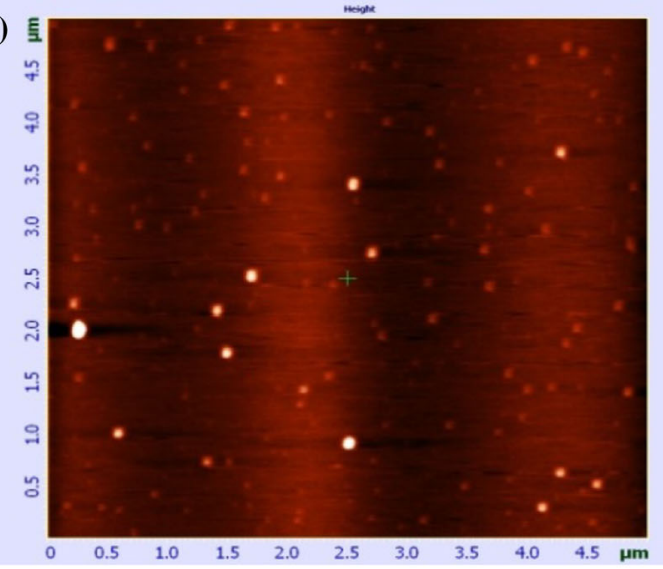

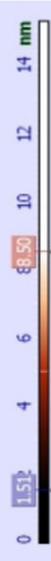

(b)

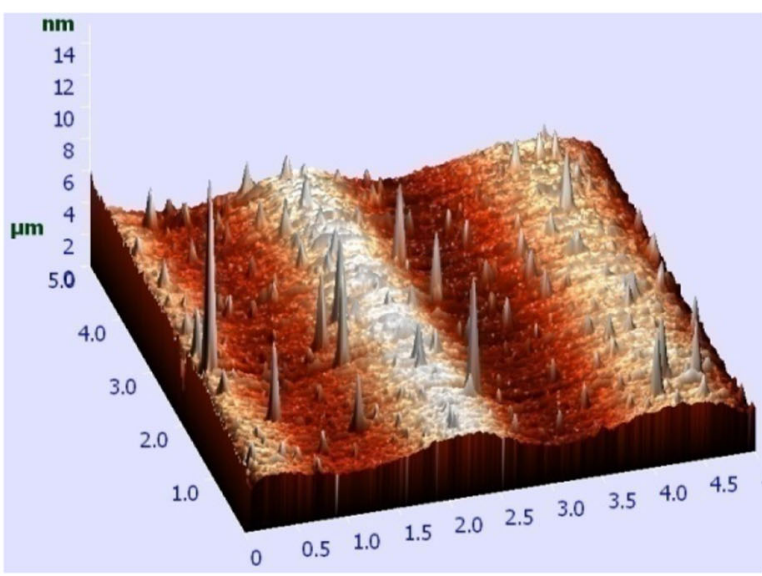

Fig. 9 a AFM 2D image. b AFM 3D image 


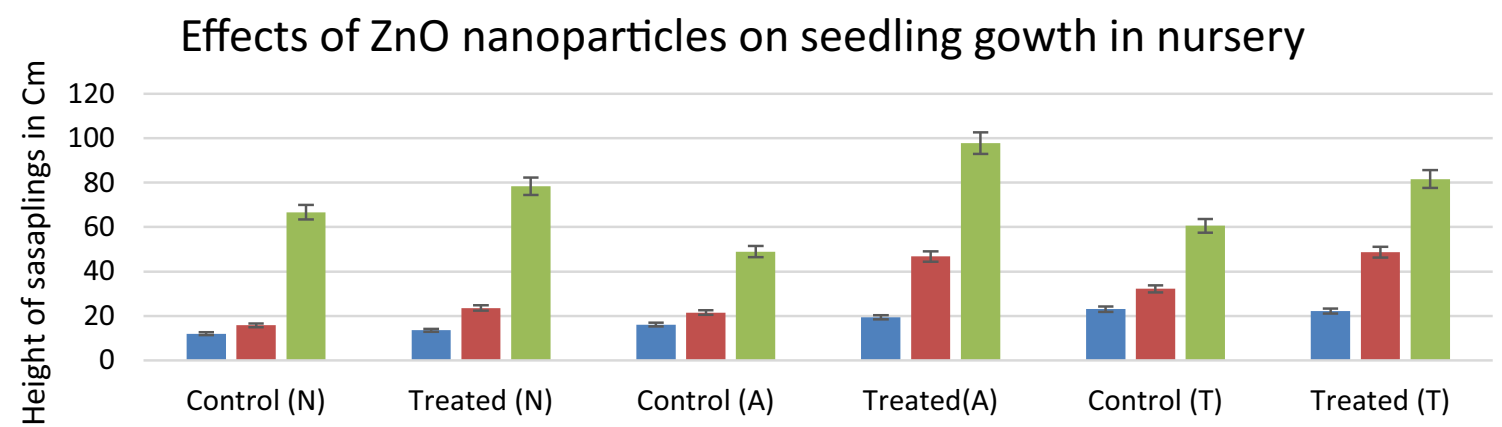

Height of different saplings: $\mathrm{N}=\mathrm{Neem}$ (Azadirachta indica ); $\mathrm{A}=$ Milkwood-pine ( Alstonia scholaris); $\mathrm{T}=$ Karanj (Pongamia pinnata)

Initial After 03 Months $\quad$ After 06 Months

Fig. 10 Effects of $\mathrm{ZnO}$ nanoparticles $(30 \mathrm{mg} / \mathrm{l})$ on growth and development of nursery saplings. Data represent mean of 50 replicates and vertical bars represent \pm standard error
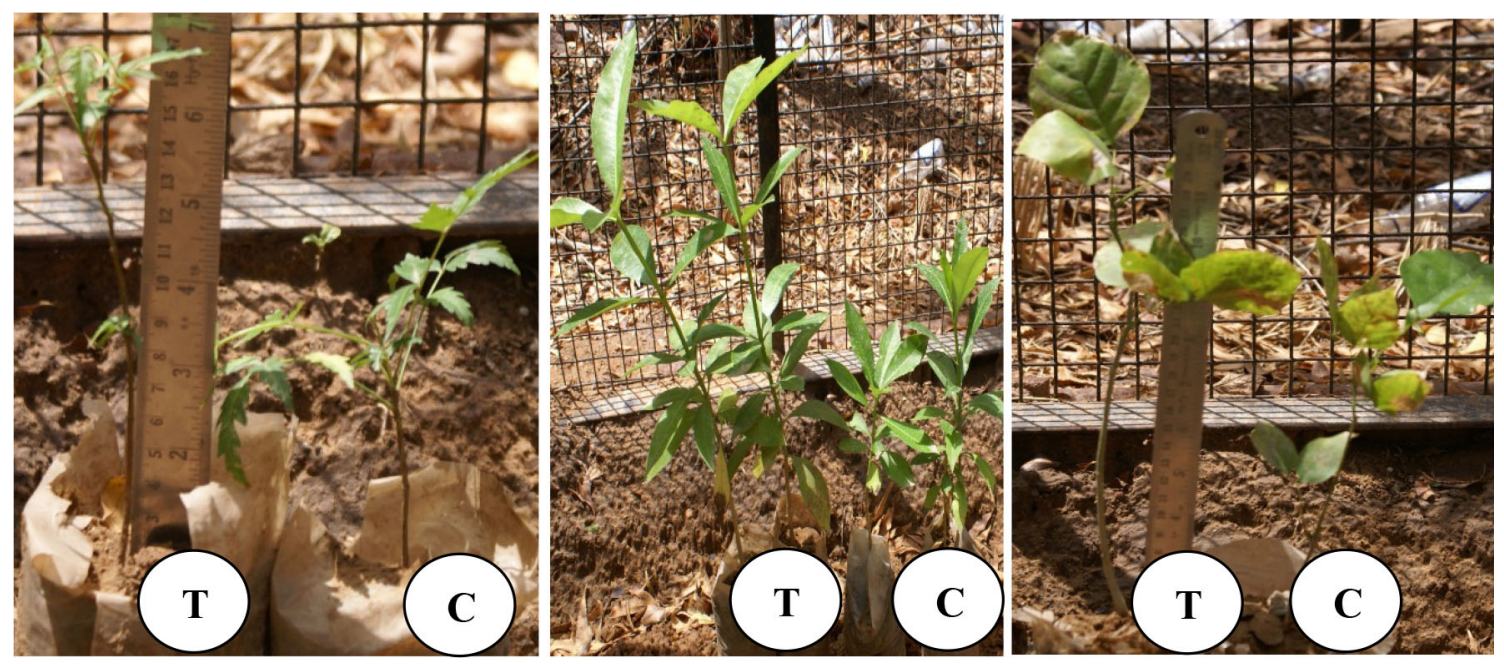

Fig. 11 Comparison between treated (T) and control (C) saplings of Azadirachta, Alstonia, and Pongamia after 3 months of ZnO nanoparticles foliar spraying (treatment)

et al. 2016) were also reported in silver nanoparticle-treated seeds of fenugreek (Trigonella foenum-graecum L.). In military camouflage applications, fast growth and large canopy trees are ideal for natural concealment. In the desert area of Rajasthan, plant growth is very much slow due to harsh climatic conditions. The formulation of nanonutrients using nanoparticles and their foliar spraying in nursery seedlings may enhance the growth and development, and stress tolerance to biotic and abiotic factors of identified saplings in nursery stage, which could be used in military camouflage package (arboriculture camouflage).

Open Access This article is distributed under the terms of the Creative Commons Attribution 4.0 International License (http:// creativecommons.org/licenses/by/4.0/), which permits unrestricted use, distribution, and reproduction in any medium, provided you give appropriate credit to the original author(s) and the source, provide a link to the Creative Commons license, and indicate if changes were made.

Publisher's Note Springer Nature remains neutral with regard to jurisdictional claims in published maps and institutional affiliations.

\section{References}

Awwad AM, Albiss B, Ahmad AL (2014) Green synthesis, characterization and optical properties of zinc oxide nanosheets using Olea europa leaf extract. Adv Mater Lett 5:520-524

Banerjee P, Satpathy M, Mukhopadhayay A, Das P (2014) Leaf extract mediated green synthesis of silver nanoparticles from widely available Indian plants: synthesis, characterization, antimicrobial property and toxicity analysis. Bioresourc Bioprocess $1: 1-10$

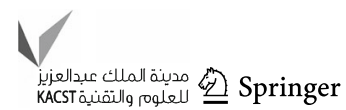


Barrena R, Casals E, Colon J, Font X, Sanchez A, Puntes V (2009) Evaluation of the ecotoxicity of model nanoparticles. Chemosphere 75:850-857

Chaudhuri SK, Malodia L (2017) Phytosynthesis and characterization of silver nanoparticles synthesized from flower extract of Roheda (Tecomella undulata G. Don). Defence Life Sci J 2:65-73

Chaudhuri SK, Chandela S, Malodia L (2016) Plant mediated green synthesis of silver naoparicles using Tecomella undulata leaf extract and their characterization. Nano Biomed Eng 8:1-8

Darrudi M, Oskuee RK, Kargar H (2013) Sol-gel synthesis, characterization and neurotoxicity effect of zinc oxide nanoparticles using gum tragacanth. Ceram Int 40:4827-4831

Devi RS, Gayathri R (2014) Green synthesis of zinc oxide nanoparticles by using Hibiscus rosa-sinensis. Int J Curr Eng Technol 4:2444-2446

Dhoke SK, Mahajan P, Kamble R, Khanna A (2013) Effects of nanoparticles suspension of mung seedlings by foliar spray method. Nanotechnol Dev 3:1-5

Divyapriya S, Sowmia C, Sasikala S (2014) Synthesis of zinc oxide nanoparticles and microbial activity of Murraya koeniggi. World J Pharm Pharm Sci 12:1635-1645

Gnanasangeetha D, Thambwani DS (2013) Biogenic production of zinc oxide nanoparticles using Acalypha indica. J Chem Biol Phys Sci 1:238-246

Herlekar H, Barne S, Kumar R (2014) Plant mediated green synthesis of iron nanoparticles. J Nanoparticles. doi:10.1155/2014/140614

Jain J, Arora S, Rajkumar JM, Khandelwal S, Pahnihar KM (2009) Silver nanoparticles in therapeutics: development of an antimicrobial gel formation for topical use. Mol Pharm 5:1388-1401

Jasim B, Roshmi T, Mathew J, Radhakrishnan EK (2016) Plant growth and diosgenin enhancement effect of silver nanoparticles in Fenugreek (Trigonella foenum-graecum L.). Saudi Pharm J. doi:10.1016/j.jsps.2016.09.012

Jayarambabu N, Sivakumari B, Prabhu YT (2014) Germination and growth characteristics of mungbean seeds affected by synthesized zinc oxide nanoparticles. Int $J$ Curr Eng Technol 5:3411-3416

Kajbafna A, Shayegh MR, Mazhammi M (2009) Nanostructure sword like $\mathrm{ZnO}$ wires: rapid synthesis and characterization through a microwave assisted route. J Alloy Compd 1:293-297

Kajbafna A, Ghorham H, Parnikar A, Sambrey JP, Sadrhezhaad SK (2012) Effects of morphology on photocatalytic performance of $\mathrm{ZnO}$ nanostructures synthesized by rapid microwave irradiation methods. Superlattices Microstruct 4:512-522

Khatami M, Pourseyedi S, Khatami M, Hamidi M, Zaeifi M, Soltani L (2015) Synthesis of silver nanoparticles using seed extract of Spinosa arvensis as a novel bioresource, and evaluation of their antifungal activity. Bioresourc Bioprocess 2:1-7
Kumar PPNV, Pammi SVN, Kollu P et al (2014) Green synthesis and characterization of silver nanoparticles using Boerhaavia diffusa plant extract and their antimicrobial activity. Ind Crops Prod 52:562-566

Mishra V, Sharma R (2015) Green synthesis of zinc oxide nanoparticles using fresh peels extract of Punica granatum and its antimicrobial activities. Int J Pharma Res Health Sci 3:694-699

Naderi MR, Abedi A (2012) Application of nanotechnology in agriculture and refinement of environment pollutants. J Nanotechnol 1:18-26

Oudhia A, Kulkarni P, Sharma S (2015) Green synthesis of ZnO nanotubes for bioapplications. Int J Curr Eng Technol 1:280-281

Panigrahi S, Kendu S, Ghosh SK, Nath S, Pal T (2004) General methods of synthesis of metal nanoparticles. J Nanopart Res 4:411-414

Razzaq A, Ammara R, Jhanzab HM, Mahmood T, Hafeez A, Hussain $S$ (2016) A novel nanomaterial to enhance growth and yield of wheat. J Nanosci Technol 2(1):55-58

Samat NA, Nor RM (2013) Sol-gel synthesis of zinc oxide nanaoparticles using Citrus aurantafolia extracts. Ceram Int 39:545-548

Seeka C, Sutthivaiyakit S (2010) Cytotoxic cardenolides from the leaves of Calotropis gigantea. Chem Pharm Bull 5:725-728

Senthilkumar SR, Sivakumar T (2014) Green tea Camellia sinensis mediated synthesis of zinc oxide nanoparticles and studies on their antimicrobial activities. Int J Pharm Pharm Sci 6:461-465

Shah V, Belozerova I (2009) Influence of metal nanoparticles on the soil microbial community and germination of lettuce seeds. Water Air Soil Pollut 197:143-148

Sindhura KS, Prasad TN, Selvam P, Hussain OM (2014) Synthesis, characterization and evaluation of effect of phytogenic zinc nanopaticles on soil exoenzymes. Appl Nanosci 4:819-827

Singh RP, Shukla P, Singh PK (2011) Biological approach of ZnO nanoparticle formation and characterization. Adv Mater Lett $2: 313-317$

Tarafdar JC, Xiang Y, Wang WN, Dong Q, Biswas P (2012) Standardization of size, shape and concentration of nanoparticle for plant application. Appl Biol Res 14:138-144

Tarafdar JC, Raliya R, Mahawar H, Rathore I (2014) Development of zinc nanofertilizers to enhance crop production in pearl millet (Pennicetum americanum). Agric Resourc 3:219-226

Thakkar KS, Mhatre SS, Parikh RY (2014) Biological synthesis of metabolic nanoparticles. Nanomedicine 2:257-262

Vidya C, Hiremath S, Chandraprabha MN, Venugopal I, Jain A, Bansal K (2013) Green synthesis of $\mathrm{ZnO}$ nanoparticle by Calotropis gigantea. Int J Curr Eng Technol 4:118-120

Wang X, Ding Y, Summers CJ, Wang ZL (2004) Large scale synthesis of $6 \mathrm{~nm}$ wide $\mathrm{ZnO}$ nanobelts. J Phys Chem 26:8773-8777 